\title{
Peroxidase Allozyme Phenotypes in Castanea and Their Segregation among Progeny
}

\section{Sandra L. Anagnostakis \\ Department of Plant Pathology and Ecology Connecticut Agricultural Experiment Station, New Haven, CT 06504}

Additional index words. chestnut, genetics

Interest in growing and breeding chestnut trees has increased with the recent publication of Bumham (1988) suggesting a backcross breeding program to improve chestnut blight resistance of American chestnut [ Castanea dentata (Marsh.) Borkh.]. American chestnuts can now be kept alive for breeding by use of a biological control based on a virus that invades the blight fungus (Anagnostakis, 1990). Santamour (1988) showed that graft compatibility in Castanea depended on the similarity of three anodal peroxidases, A, B, and $\mathrm{C}$.

I have modified his technique and checked 10 trees of C. mollissima B1., 11 C. dentata, three $C$. sativa Mill., three C. crenata Sieb. \& Zucc., two C. seguinii Dode, and one C. henryi (Skan) Rehd. \& Wils. The hybrids investigated were $F_{1} s$, with American as one parent, $\mathrm{F}_{2} \mathrm{~s}$, and first generation backcrosses (BC1) to American. All trees were growing at the Sleeping Giant Chestnut Plantation, or at the Lockwood Farm, Connecticut Agricultural, Experiment Station, both in Hamden, Conn. The plot maps are available from the director, Connecticut Agricultural Experiment Station.

Twigs with dormant buds were harvested

Received for publication 18 Mar. 1991. The cost of publishing this paper was defrayed in part by the payment of page charges. Under postal regulations, this paper therefore must be hereby marked advertisement solely to indicate this fact. and stored in plastic bags in a freezer at - 20C until used. For extraction, three buds were removed from the twigs and placed in a glass homogenizer with $0.5 \mathrm{ml}$ of a solution containing $0.1 \mathrm{M} \mathrm{N}$-2-hydroxyethylpiperazineN'3-propanesulfonic acid (EPPS; Sigma Chemical Co., St. Louis), $5 \mathrm{~mm}$ potassium metabisulfite, $10 \mathrm{~mm}$ cysteine, and $1 \%$ Tween 80 , adjusted to $\mathrm{pH} 7.0$. The buds were ground and transferred to microcentrifuge tubes (Eppendorf, Fremont, Calif), centrifuged (at 4C) to a firm pellet, and the supernatants transferred to new tubes. Electrophoresis was performed on $7 \%$ native polyacrylamide gels in Tris-glycine buffer, $\mathrm{pH} 8.9$, for $\approx 7 \mathrm{~h}$ at $30 \mathrm{~mA}$ per gel (vertical electrophoresis apparatus cooled to $10 \mathrm{C}$ ). Gels were stained to detect peroxidase activity by allowing them to react with $\mathrm{H}_{2} \mathrm{O}_{2}(0.5 \mathrm{ml}$ of a $3 \%$ solution in $50 \mathrm{ml}$ ) and 3-3'-diaminobenzidine (Sigma, $0.25 \mathrm{mg}$ in $50 \mathrm{ml})$ in $0.2 \mathrm{M}(2-(\mathrm{N}$-morpholino)ethanesulfonic acid (MES; Sigma), $\mathrm{pH}$

Many anodal bands were seen, but the consistent bands, referred to as bands $\mathrm{A}$ and B by Santamour et al. (1986), near the origin were easily identified. None of the slowermoving bands that Santamour called $\mathrm{C}$ were found. All 11 trees of $C$. dentata and three trees of C. sativa had only the A allozyme. Three trees of $C$. crenata, two of $C$. seguinii, and the only $C$. henryi had only the $\mathrm{B}$ allozyme. Among 10 trees of C. mollissima one had only A, five had only $\mathrm{B}$, and four had A and B. This distribution is consistent with previous observations of Santamour et al. (1986).

Hybrids of $C$. crenata x $C$. dentata (two trees) and two of $C$. dentata $\times$. seguinii had both A and B. Two of $C$. dentata x $C$. mollissima had both $\mathrm{A}$ and $\mathrm{B}$, two of $C$. mollissima x $C$. dentata had $\mathrm{A}$ and $\mathrm{B}$, and one had only A. Two hybrids $[(C$. crenata х $C$. dentata) $\mathrm{x}(C$. mollissima $\mathrm{x} C$. dentata $)]$ had only A.

Two clones of the BC1 tree 'Clapper' had only A, and BC1 tree 'Graves' had both A and $\mathrm{B}$. These trees are both $(C$. mollissima x $C$. dentata) х $C$. dentata.

New BC1 trees (seed planted Mar. 1989, and twigs harvested Dec. 1990) that had Asian hybrid parents with both A and B crossed with American trees with only A would have segregated $1: 1$ for $\mathrm{AA}: \mathrm{AB}$ if $\mathrm{A}$ and $\mathrm{B}$ were alloyzmes determined by alleles at the same locus. Both kinds of crosses yielded more progeny with the peroxidase phenotype AA than expected. The peroxidase phenotypes of (C. mollissima х $C$. dentata) х $C$. dentata progeny from 10 crosses were $37 \mathrm{AA}$ and $26 \mathrm{AB}$, but the deviation from 1:1 was not significant (chi-square analysis yielded $P=$ $0.16)$. Five crosses of $C$. dentata $\times(C$. crenata $\mathrm{x} C$. dentata) yielded $19 \mathrm{AA}$ and $12 \mathrm{AB}$, which is also not significantly different from 1:1 (chi-square analysis yielded $P=0.21$ ). These results support the prediction of Santamour et al. (1986) that these important peroxidases are allelic.

\section{Literature Cited}

Anagnostakis, S.L. 1990. Improved chestnut tree condition maintained in two Connecticut plots after treatments with hypovirulent strains of the chestnut blight fungus. Forest Sci. 36:113-124.

Burnham, C.R. 1988. The restoration of the American chestnut. Amer. Scientist 76:478-487.

Santamour, F.S., Jr. 1988. Graft incompatibility related to cambial peroxidase isozymes in Chinese chestnut. J. Environ. Hort. 6:33-39.

Santamour, F.S., Jr., A.J. McArdle, and R.A. Jaynes. 1986. Cambial isoperoxidase patterns in Castanea J. Environ. Hort. 4:14-16. 